\title{
Drop Metastasis in the Spinal Cord
}

National Cancer Institute

\section{Source}

National Cancer Institute. Drop Metastasis in the Spinal Cord. NCI Thesaurus. Code C5439.

An intradural extramedullary spinal metastasis from an intracranial tumor through the cerebrospinal fluid. 